
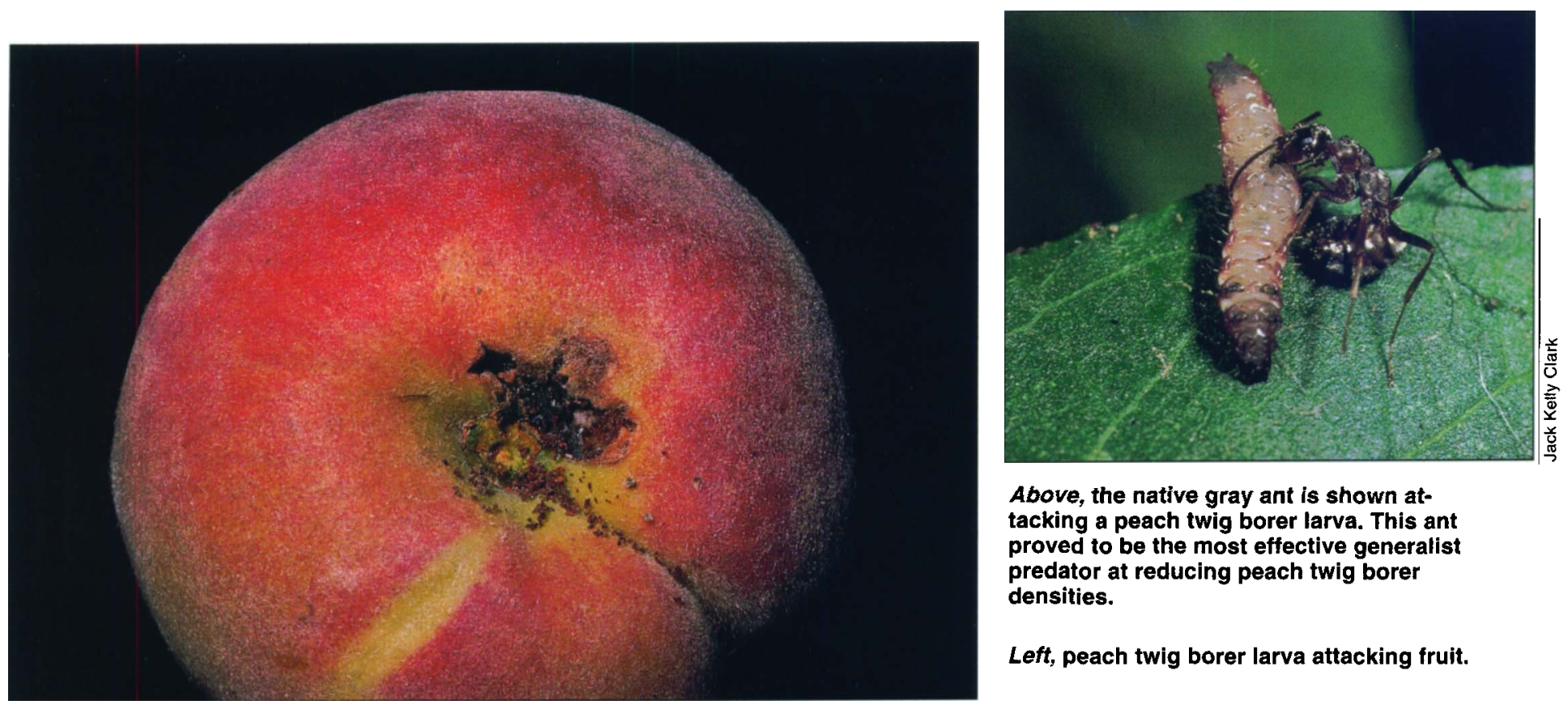

Above, the native gray ant is shown attacking a peach twig borer larva. This ant proved to be the most effective generalist predator at reducing peach twig borer densities.

Left, peach twig borer larva attacking fruit.

\title{
Native gray ant has beneficial role in peach orchards
}

Kent M. Daane a Jeffrey W. Dlott

The effectiveness of resident insect predators as biological control agents of peach twig borer was tested in a series of field experiments. Results showed that the native gray ant was the most common and effective generalist predator. Treatments with native gray ant present had significantly lower peach twig borer abundance and peach shoot damage. Ant population densities were studied in seven commercial orchards. Results showed that although this ant is found in most peach and nectarine orchards, its abundance was not clearly associated with any single cultural practice and may be difficult to manipulate.

Ants are common generalist predators in landscape and agricultural systems. Nevertheless, most ant species are known as orchard pests because they feed directly on the crop or disrupt biological control. For example, the southern fire ant, Solenopsis xyloni, damages almond nuts on the ground. Other ant species have mutualistic associations with honeydew-producing insect pests. The Argentine ant, Linepithema humile, "tends" aphids for the carbohydrate-rich honeydew the aphids excrete. In return, the ants attack parasites and predators of the aphids. Nevertheless, not all ant species are always orchard pests. This article presents results from studies in peach and nectarine orchards that highlight the beneficial role of the native gray ant, Formica aerata, in the control of the peach twig borer (PTB),

Anarsia lineatella.

The native gray ant is resident in California and parts of Nevada and Oregon. It is a large (about 0.25 inch), dark-gray ant. Native gray ant nests are commonly hidden under the soil or in the decaying wood of tree trunks and roots. The ants exit the nest through cracks in the soil surface and forage individually for food on the ground or in the trees. For these reasons, native gray ants may be less apparent than other ant species that have nests with very noticeable "ant hills" (such as fire ants) or that forage in large numbers along well-defined "ant trails" (such as Argentine ants). In the native gray ant colony there is a social structure, with a "queen" that produces eggs and "workers" that tend the queen and care for the developing ant larvae.

The workers also forage for food, collecting carbohydrates (such as insect honeydew or plant nectar) and proteins (such as PTB larvae) that they take to the nest to feed the immature ants. Because the native gray ant tends insects for carbohydrates, there can be situations when it is a pest. Shorey et al. (1993) reported that native gray ants tend several aphid species in plum trees and therefore can disrupt biological control of these honeydewproducing insects. However, aphid 
and soft scale pest outbreaks are not common in peaches, nectarines and almonds, and for this reason the native gray ant can potentially play a singularly beneficial role.

PTB is a moth; its larvae damage nuts or fruit in almond, peach, nectarine, plum and prune orchards. Its life cycle is fairly simple. PTB overwinters as a larva that bores into the crotch of 2-to-3-year-old wood and forms a hibernaculum. The larva emerges from the hibernaculum in spring and attacks buds and young shoots. During the growing season, PTB has three or four generations. Its larvae spend most of their immature life feeding inside freshly growing shoots or on fruit or nuts. The larvae pupate inside crevices or cracks on the tree or fruit, with adult emergence marked by peak flight periods in each generation.

Our studies of native gray ants and other generalist predators began after we observed some untreated peach orchards with less than 3\% PTB fruit damage, while some orchards that received insecticides had more than $5 \%$ damage. (Economic tolerance is usually less than $3 \%$ fruit damage.) We wanted to determine which factors resulted in the low PTB damage levels observed in those untreated orchards.

We knew from earlier surveys that parasite activity was low, accounting for less than 5\% parasitism (Daane et al. 1993). There were, however, numerous generalist predators, such as lacewings, active in the orchards (Dlott et al. 1994). We also knew, from earlier studies, that excess nitrogen fertilization led to an unnecessary increase in vegetative shoot growth and a related increase in PTB density (Daane et al. 1995). Such observations suggested PTB mortality resulted from generalist predators or from physical factors such as climate or host plant condition. Our goal was to determine the levels of PTB mortality from biological factors, such as predators, and from physical factors. To accomplish this, we conducted experiments that manipulated the number and species of generalist predators on peach shoots. These experiments were timed to coincide with (1) the emergence of overwintering PTB larvae in spring and (2) egg hatch in summer to provide an indication of naturally occurring PTB mortality. We also present results from a 1-year study of ant abundance in seven different orchards, in which we attempted to correlate native gray ant abundance to cultural practices.

\section{Exclusion experiments}

We conducted experiments in a 3 year-old peach orchard ('Diamond Princess') in Dinuba and in a 12-yearold peach orchard ('Flamecrest') in

TABLE 1. Average daily relative abundance of predators per tested branch in no exclusion and partial exclusion treatments timed to coincide with the overwintering (OW), first and second generations of peach twig borer (PTB)*

\begin{tabular}{|c|c|c|c|c|c|c|}
\hline $\begin{array}{c}\text { РTB } \\
\text { generation }\end{array}$ & $\begin{array}{l}\text { Exclusion } \\
\text { treatment }\end{array}$ & $\begin{array}{c}\text { Native } \\
\text { gray ants }\end{array}$ & $\begin{array}{c}\text { Lady } \\
\text { beetles }\end{array}$ & $\begin{array}{c}\text { Green } \\
\text { lacewings }\end{array}$ & $\begin{array}{c}\text { Minute } \\
\text { pirate bugs }\end{array}$ & Spiders \\
\hline \multirow[t]{2}{*}{ OW 1992} & None & 0.0367 a† & $0.0388 a$ & $0.0017 a$ & - & - \\
\hline & Partial & $0.0100 \mathrm{~b}$ & $0.0321 \mathrm{a}$ & $0.0050 \mathrm{a}$ & - & - \\
\hline \multirow[t]{2}{*}{ OW 1993} & None & 0.0357 a & $-\ddagger$ & - & - & - \\
\hline & Partial & $-b$ & - & - & - & - \\
\hline \multirow[t]{2}{*}{ First 1993} & None & $0.0312 a$ & $0.0219 a$ & $0.1188 \mathrm{a}$ & $0.0063 a$ & - \\
\hline & Partial & $-b$ & $0.0125 a$ & $0.1188 \mathrm{a}$ & $0.0094 a$ & - \\
\hline \multirow[t]{2}{*}{ Second 1993} & None & $0.3520 \mathrm{a}$ & - & $0.0640 \mathrm{a}$ & - & $0.039 a$ \\
\hline & Partial & $0.0040 \mathrm{~b}$ & - & $0.0780 a$ & - & $0.035 \mathrm{a}$ \\
\hline
\end{tabular}

"Mean daily relative abundance of predators was determined from samples taken at days $8,9,10$ and 11 (overwintering generation 1992); 4, 7, 11, 14, 18, 21 and 25 (overwintering generation 1993); 5, 7, 10, 14 and 19 (first generation 1993) and 7, 10,14 and 17 (second generation) after the peach twig borer larvae were placed on treatment shoots. Means were determined including zero values that indicated that no predator was found during a particular 30 -second observation period.

+ Within each trial, means in the same column followed by the same letter are not significantly different $(P>0.05$, ANOVA).

$\ddagger$ Indicates that predators were rare $(<0.001)$ or absent during the sampling periods.

Kingsburg. Both orchards were managed within the guidelines of California Certified Organic Farmers. Insect pest management procedures at the Dinuba orchard were a dormant-season application of oil for San Jose scale (Rice and Jones 1988); pheromone confusion for the Oriental fruit moth (Grapholita molesta) (Rice and Kirsch 1990); and a seeded cover crop to enhance beneficial insects (Hendricks 1995). Insect pest management procedures at the Kingsburg orchard were similar, the only exception being bloom-time applications of Bacillus thuringiensis for PTB (Barnett et al. 1993).

Predators of larvae. At each site, trees were randomly selected from a 60 - or 100-tree block and three branches were chosen from the upper canopy of each selected tree. The three branches were either (1) enclosed in an organdy cage; (2) partially isolated by a barrier of Tanglefoot placed around the base of the selected branch; or (3) open (no cage or Tanglefoot barrier). These treatments are referred to as full, partial and no exclusion, respectively. The full exclusion treatment was designed to exclude all predators, thereby providing an estimate of mortality from physical factors alone. The partial exclusion treatment was designed to remove the effect of predation by the native gray ant and other walking predators. The no exclusion treatment was designed to estimate the combined mortality from both biological and physical factors. All trials were set in a randomized complete block design with either six (overwintering, 1992) or five (overwintering and first and second summer generations, 1993) blocks each with five trees per block.

To begin each experimental trial, a small PTB larva was placed on each tested branch. Every 2 or 3 days thereafter, the number of peach shoots attacked by PTB was recorded. This information provided the PTB shoot attack rates and the number of feeding sites per larva. Also on a 2- or 3-day schedule, shoots in the no exclusion and partial exclusion treatments were monitored between 9 a.m. and 2 p.m. During 30 -second observation periods, 
natural enemy species composition and relative abundance were measured. The experiments were concluded when PTB larval development was nearly complete (fifth instar). On the last sampling date, the tested branches were removed and dissected, and the stages of recovered larvae were recorded.

Predators of pupae. At the Kingsburg site, we determined the level of pupal predation. Experiments were timed to coincide with the natural pupation periods for the first, second and third PTB summer generations, using adult flight to monitor resident PTB development (Rice et al. 1982). For the no exclusion treatment, PTB that had pupated in small, corrugated paper squares (simulating field pupation sites) were pinned flush to the surface of tree bark on the peach scaffolding. For the full exclusion treatment, pupae (also in corrugated cardboard) were placed in small plastic or organdy cages and pinned to the tree bark. After 5 days, the condition of the pupae was recorded. A randomized block design, with 20 replicates, was used for each trial.

Statistical analysis. Analysis of variance was used to test for effect of treatment and block on predator abundance, larval shoot attack rate and larval survival. A two-tailed t-test was used to compare pupal survival and average number of damaged shoots per recovered larva in the no exclusion and partial exclusion treatments. Levels of significance for all tests were $P<0.05$.

\section{Gray ants excluded}

Predators of larvae. Generalist predators found foraging on branches in the no exclusion treatment included the native gray ant, convergent lady beetle (Hippodamia convergens), green lacewings (Chrysoperla carnea, Chrysoperla comanche and Chrysopa nigricornis), minute pirate bugs (Orius spp.) and two salticid spiders (Metaphidippus vitis and Thiodina spp.). In the partial exclusion treatment, native gray ant abundance was significantly lower than in the no exclusion treatment (table 1). The abundance of all other generalist predators was not sig-
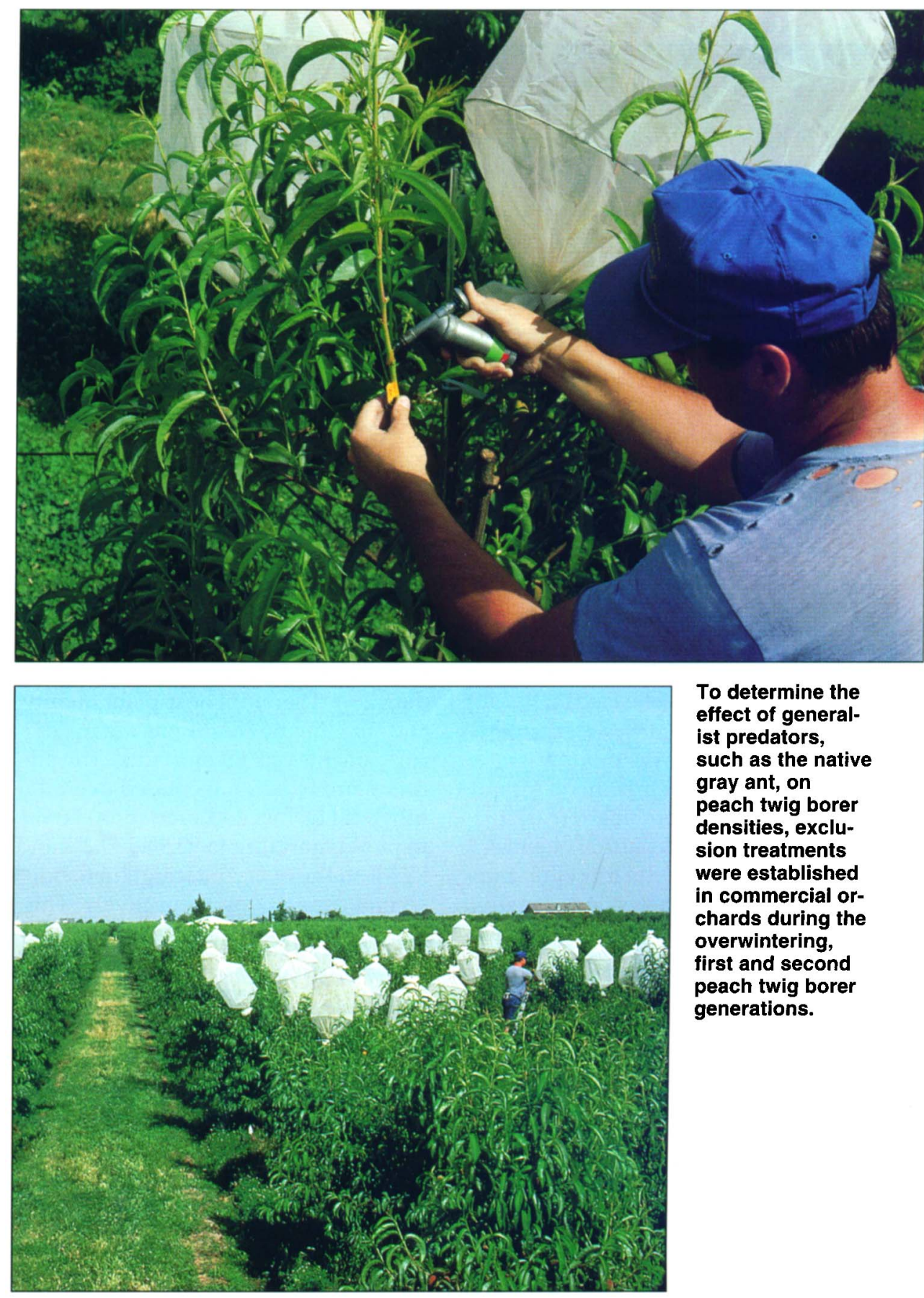

To determine the effect of generalist predators, such as the native gray ant, on peach twig borer densities, exclusion treatments were established in commercial orchards during the overwintering, first and second peach twig borer generations.

nificantly different between these two treatments. This indicates that the Tanglefoot barrier reduced predation pressure only from native gray ants. (Field observations suggest that other solely ambulatory predators, such as green lacewing larvae, were placed on the tested branches as eggs, by winged adults.) Of course, no predators were observed in the full exclusion treatment.

Shoot damage. Our first question was whether or not we had successfully inoculated tested branches with insectary-reared PTB larvae. Results showed that average shoot attack rates ranged from $58 \%$ to $89 \%$, indicating that shoots were successfully inoculated. The average number of feeding sites per surviving larva was $2.8 \pm 0.1$. Because each larva requires more than one vegetative shoot to complete its development, it would be exposed to foraging predators each time it moved to a new feeding site. This is an important part of the predator-prey interaction, as observations indicate that native gray ants can kill PTB larvae only when the pest is outside the shoot. We 


\section{Life Tables}

To determine the amount of peach twig borer (PTB) mortality resulting from biological factors such as predators and physical factors such as climate and host plant condition, we used data collected in the exclusion experiments to construct life tables.

A life table is an age-specific summary of the mortality of a population. In its simplest form, a life table can show the death rates of a cohort of individuals. We started with the number of PTB alive in each stage $\left(l_{x}\right)$. In this case, the number alive began at five first instars. We recorded the number of PTB larvae or pupae that died in each stage $\left(d_{x}\right)$. Combining these data points, we were able to determine the mortality rate for each stage $\left(q_{x}=d_{x} / l_{x}\right)$. Mortality caused by physical factors was represented by the mortality rate in the full exclusion treatment. Mortality caused by the combination of physical factors and natural enemies was represented by the mortality rate in the no exclusion treatment. Finally, comparing mortality in the no exclusion to the partial exclusion treatments, we were able to estimate the mortality caused by the native gray ant (see Bellows et al. 1993 for details of methodologies used). Using these techniques, we created partial life tables. We collected no data on egg or adult mortality rates. As an example, we provide one of the four life tables created.

Life-table analysis found that physical factors caused $65.2 \%, 57.7 \%$ and $72.4 \%$ of the PTB larval mortality in the overwintering (1992 and 1993 combined), first and second generations, respectively. For pupae, mortality from physical factors was small (less than $2 \%$ ). Therefore host-plant quality and/or climatic conditions are major components of PTB mortality. The addition of predation increased overall (physical factors and predation) larval to pupal mortality to $93.9 \%, 90.2 \%$ and $98.0 \%$ in the overwintering, first and second generations, respectively. This indicates that predators added an additional mortality of $28.7 \%, 32.5 \%$ and $25.6 \%$ in each of these respective periods. Using data from the partial exclusion treatment, we determined that the native gray ant was the most important predator of second to fifth instar PTB in three of four trials, accounting for $89.2 \%$ and $71.4 \%$ of the predator mortality in overwintering generations (1992 and 1993, respectively) and $59.1 \%$ in the first summer generation (1993). Pupal predation rates were estimated at $45.5 \%$ and $30.4 \%$ for the first and second summer generations. We cannot assign pupal mortality to any single predator species, although the native gray ant was one of the most common predators found foraging on the peach scaffolding.

\section{References}

Bellows TS, Van Driesche RD, Elkinton JS. 1992. Life-table construction and analysis in the evaluation of natural enemies. Ann Rev Entomol 37:587-614.

TABLE 1. Partial life table for peach twig borer larval and pupal stages constructed from predator exclusion treatments coinciding with the first generation in 1993

\begin{tabular}{|c|c|c|c|c|c|}
\hline Treatment & Mortality factor & $\begin{array}{c}\text { Number alive at } \\
\text { start of each stage }\left(I_{x}\right)\end{array}$ & $\begin{array}{l}\text { Number killed } \\
\text { in each stage }\left(d_{x}\right)\end{array}$ & $\begin{array}{l}\text { Stage mortality } \\
\text { rate }\left(q_{x}\right)\end{array}$ & $\begin{array}{l}\text { Cohort mortality } \\
\text { rate }\left(d_{x} / I_{1}\right)\end{array}$ \\
\hline \multicolumn{6}{|l|}{ Full exclusion } \\
\hline First instar & Physical & 5.000 & 1.063 & 0.213 & 0.213 \\
\hline Second to fifth instar & Physical & 3.938 & 1.646 & 0.418 & 0.329 \\
\hline Pupa* & Physical & 2.292 & 0.176 & 0.077 & $\begin{array}{r}0.035 \\
-0.577\end{array}$ \\
\hline \multicolumn{6}{|l|}{ Partial exclusiont } \\
\hline First instar & Physical \& biologicalł & 5.000 & 1.250 & 0.250 & 0.251 \\
\hline Second to fifth instar & Physical \& biologicalł & 3.750 & 1.313 & 0.350 & $\begin{array}{r}0.262 \\
\text { Total }= \\
0.513\end{array}$ \\
\hline \multicolumn{6}{|l|}{ No exclusion } \\
\hline \multirow[t]{2}{*}{ First instar } & Physical & 5.000 & 1.063 & 0.213 & 0.213 \\
\hline & Biological & 3.938 & 0.750 & 0.190 & 0.150 \\
\hline \multirow[t]{2}{*}{ Second to fifth instar } & Physical \& biological & 3.188 & 0.896 & 0.281 & 0.179 \\
\hline & Native gray ant§ & 2.292 & 1.354 & 0.591 & 0.271 \\
\hline \multirow[t]{3}{*}{ Pupa } & Physical & 0.938 & 0.072 & 0.077 & 0.014 \\
\hline & Predation & 0.866 & 0.375 & 0.433 & 0.075 \\
\hline & & & & & Total $=0.902$ \\
\hline
\end{tabular}

* The estimated pupal mortality rate is taken from the experiment coinciding with the first generation for the no exclusion (7.7\% mortality) and full exclusion $(50.0 \%$ mortality) treatments; predator mortality is estimated from the difference between these values $(50.0-7.7=43.3 \%)$. Mortality from predation is due to unspecified generalist predators.

$\dagger$ No estimate for pupal mortality is given because the pupal predation experiment did not include a partial exclusion treatment.

$\mp$ It is not possible to separate the effects of predation from other mortality factors because, in this trial, there was not a significant difference between survival rates in the full and partial exclusion treatments.

$\S$ Mortality from the native gray ant can be assigned in assigned in trials when a significant difference exists between predator species presence in the partial and no exclusion treatments (see table 1, page 26). 
also noted that the average number of feeding sites per larva changes depending on host plant condition. When shoot growth is poor, more feeding sites are required. Therefore nitrogen fertilization regimes that decrease vegetative growth can potentially reduce PTB numbers in two ways: PTB larvae would have fewer host sites and larvae that spend more time foraging for host sites would be exposed to predators for greater periods of time.

Most importantly, there was a treatment effect on the number of shoots attacked and PTB survival. We found no significant differences in shoot attack rates between the full exclusion treatment (no predators) and the partial exclusion treatment (all predators except for the native gray ant). However, in two of four trials, shoot attack rates were significantly lower in the full exclusion versus the no exclusion treatment (all predators, including the native gray ant) (fig. 1A). These results suggest that predators affected PTB density. In fact, in three of four trials, PTB larval survival was significantly lower in the no exclusion versus the partial or full exclusion treatment (fig. 1B). Because the native gray ant was the only predator significantly reduced from the partial exclusion treatment (table 1), we conclude that ants accounted for the reduced shoot attack rates and PTB survival observed. Because there were significant differences in shoot attack rates in only two of four trials and PTB survival in three of four trials, results also suggest that the impact of predation is small and varies between generations and years (see sidebar).

Pupal survival. When predators were excluded, pupal survival was high $(92.3 \% \pm 5.2 \%, 86.1 \% \pm 5.7 \%$ and $91.7 \% \pm 7.0 \%$ in the trials conducted in the first, second and third PTB generations, respectively). This indicates that there is little pupal mortality from physical factors, such as climate. In comparison, when predators were not excluded, PTB pupal survival was significantly lower $(50.0 \% \pm 7.0 \%, 37.5 \% \pm$ $7.4 \%$ and $63.9 \% \pm 9.6 \%$, in the same respective PTB generations). We conclude therefore that predators significantly reduced the number of PTB pupae. The natural enemy species most responsible for pupal predation could not be determined because separation of predator species was not made; however, native gray ants and southern fire ants were the predators most commonly found foraging on tree trunks.

\section{On-farm studies}

After identifying the native gray ant as the most important PTB predator, the question remains whether or not its numbers can be manipulated to improve pest management. To answer this, we investigated the relationship between ant levels and orchard management practices in seven orchard blocks that had different management practices. At each site, ants were sampled every 2 weeks from January to December 1994 by placing tuna-fish bait stations at the base of 60 trees at each site. After about 30 minutes, the number of bait stations occupied by ants was recorded. We were especially careful to record the numbers of different ant species because earlier observations suggested that native gray ants and southern fire ants may compete for nesting sites and foraging territories.

Statistical analysis. The bait-station data of ant species presence or absence was placed into a "2-by-2 contingency" table format. A chi-square test for independence was then used to determine whether a relationship existed between the foraging patterns of native gray ants and southern fire ants. Levels of significance for all tests were $P<0.05$.

\section{Gray, southern fire ants compete}

Ant species. The native gray ant and the southern fire ant were the most dominant ant species at the bait
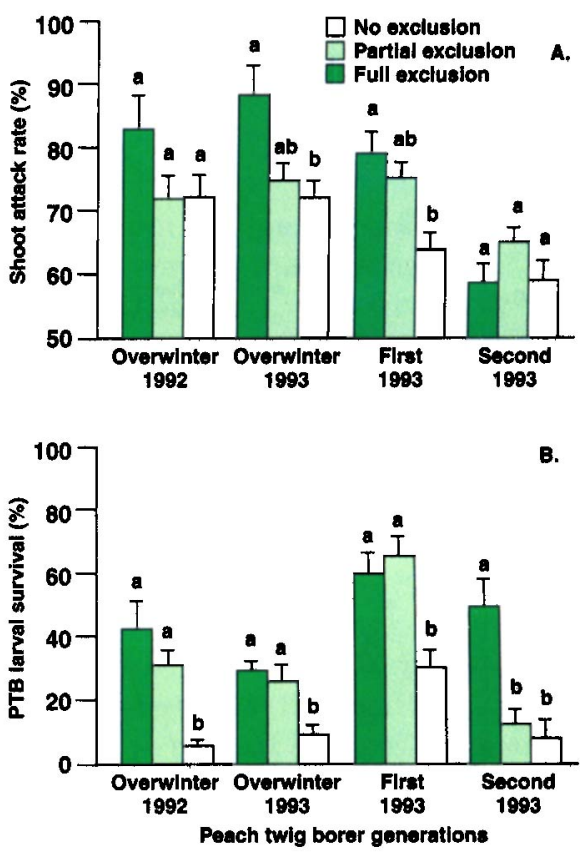

Fig. 1. Peach twig borer (A) shoot attack rates (mean \pm SEM) and (B) survival rates (mean \pm SEM) for full, partial and no exclusion treatments in trials coinciding with overwintering (1992 and 1993), first (1993) and second (1993) peach twig borer generations. Averages in each trial with the same letter are not significantly different (Tukey's HSD test, $P>0.05$ ). 
stations. Native gray ants began foraging earlier than fire ants and quickly occupied more than $50 \%$ of the bait stations (fig. 2). This time period coincides with budbreak, the first appearance of extrafloral nectar on new shoot growth and the emergence of PTB larvae from hibernaculae. Native gray ant foraging activity continued from February to December. The southern fire ant had a shorter foraging period, with activity concentrated in summer and fall. Results suggest that there is competition between these two ant species. Chi-square tests indicate that the observed frequencies of encounters between the two ant species were significantly lower than what would be expected if encounters occurred at random (table 2). This indicated a territorial foraging behavior for these species. In other words, the native gray ant and southern fire ant competed for resources, and when one species was high in numbers, the other was likely to be low in numbers.

Competitive interactions between these species are important because the southern fire ant was rarely observed foraging on the shoot terminals and is not an important PTB predator.

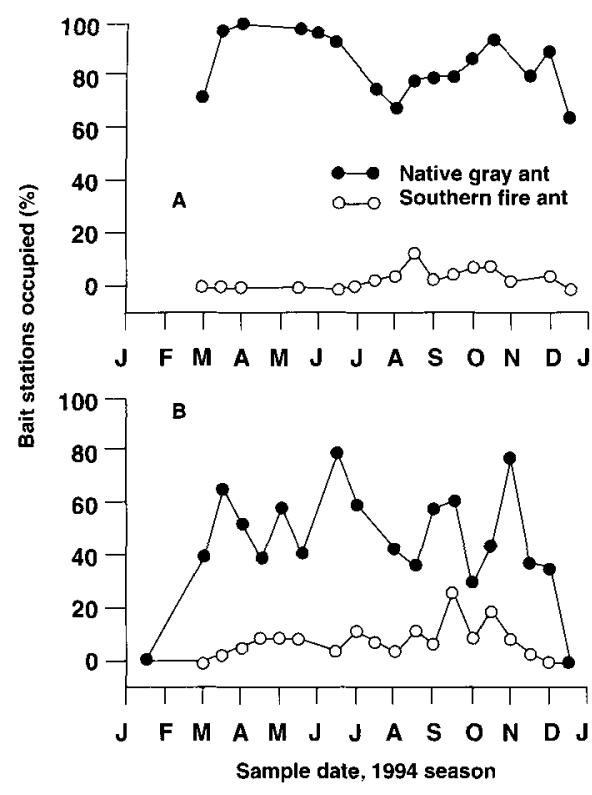

Fig. 2. Percentage bait stations occupied by the native gray ant and southern fire ant orchards with $(A)$ herbicide and disking to maintain a clean-cultivated orchard floor and (B) seeded cover crops and resident vegetation on berms and row middles.
In fact, it is almost always considered a pest. Ant foraging strategies are often divided into individual and social processes, and there is ample opportunity for competition between these ant species in each category. Both nest in the soil, forage on the ground cover or trees and often aggregate around abundant food sources. For example, a single foraging ant may find a bait station (individual process) and then recruit other workers (social process), which then defend the food source from competing ants. Field observations showed the southern fire ant to more aggressively recruit other workers to aggregate to and defend a food source. These defensive behaviors between foragers could result in spatial separation of native gray ant and southern fire ant colonies. Therefore high southern fire ant population densities might lower native gray ant numbers.

Cultural practices. In the seven orchards monitored, the impact of floor management practices on native gray ant or southern fire ant abundance was not easily determined. We found both low and high ant abundance in orchards with all combinations of floor management practices monitored, which included (1) year-round cover crops and/or resident vegetation; (2) a combination of cover crops and cross disking; (3) no cover crops maintained by in-row disking; and (4) no cover crops maintained by herbicide applications. These results suggest that the native gray ant is a robust species that is able to survive in disturbed settings.

The only cultural practice that dramatically lowered native gray ant abundance was an in-season (for example, May, June, July, August) application of an organophosphate, carbamate, or pyrethroid insecticide, which resulted in a sharp decrease in the percentage of bait stations occupied. However, the ant populations were not eliminated from these orchards, and eventually recovered in numbers. We believe that the impact of insecticides was dampened because they killed only foraging ants, and much of the ant population was protected underground in the ant colony. Insecticides with a longer residual ac- tivity would have a greater impact on ant numbers because more foragers are likely to be eliminated. For similar reasons, a dormant-season application of an organophosphate did not lower native gray ant numbers because there was little to no ant foraging in December and January. On those farms that received a dormant season organophosphate (and no in-season insecticides, except for Bt), more than $90 \%$ of bait stations were eventually colonized by native gray ants during the summer, which was equivalent to levels observed at farms that did not receive any dormant sprays.

\section{Gray ant is important predator}

Predator exclusion experiments showed that the native gray ant is the most important PTB predator. Further, the natural foraging of these ants resulted in a significant decrease in PTB larval abundance and shoot infestation levels. Our field observations also found that the native gray ant feeds on peach extrafloral nectar, and may be foraging on the peach tree primarily for this carbohydrate source. It is important to remember that most peach and nectarine cultivars do not have significant problems with aphids or soft scales, and therefore the native gray ant does not have the opportunity to tend these insect pests and disrupt biological control.

One surprising find was the lack of any relationship between orchard floor management practices and native gray ant numbers. Cover crops or resident vegetation can provide alternative food sources in the form of alternative prey, seeds or nectar. And yet our data suggest that native gray ant populations can be found in all kinds of ecosystems, including clean cultivation. However, cover cropping and/or disking may still benefit native gray ant populations by reducing abundance of southern fire ant, which prefers dry, undisturbed soils. Because the native gray ant and southern fire ant compete for foraging territory, any cultural practice that decreases one species may allow the other species to increase in numbers. A better understanding of orchard floor management strategies that might simultaneously 
encourage native gray ant populations and reduce southern fire ant abundance is needed.

K.M. Daane is Associate Specialist, Center for Biological Control, Division of Insect Biology, Department of ESPM, UC Berkeley (stationed at the Kearney Agricultural Center in Parlier); and J.W. Dlott is Senior Researcher, Dlott $\mathcal{E}$ Associates Consulting, Santa Cruz. We would like to thank Paul Buxman and Dick and Karen Peterson for use of their farms; the California Clean Growers Association for help in the development of grower-collaborative research; Andy Gutierrez and Charlie Summers for helpful suggestions; Matt Jones, Ingrid Peterson and Glenn Yokota for laboratory and fieldwork; and the California Tree Fruit Agreement, California Cling Peach Board, California Energy Commission, and Switzer Foundation Environmental Fellowship for funding.

\section{References}

Barnett WW, Edstrom JP, Coviello RL, Zalom FG. 1993. Insect pathogen Bt controls peach twig borer on fruits and almonds. Cal Ag 47(5):4-6.

Daane KM, Johnson RS, Michailides TJ, et al. 1995. Nitrogen fertilization affects nectarine fruit yield, storage qualities, and susceptibility to brown rot and insect damage. Cal Ag 49(4):13-8.

Daane KM, Yokota GY, Dlott JW. 1993 Dormant-season sprays affect the mortality of peach twig borer (Lepidoptera: Gelechiidae) and its parasitoids. J Econ Entomol 86:1679-85.

Dlott JW, Altieri MA, Masumoto M. 1994. Exploring the theory and practice of participatory research in US sustainable agriculture: A case study in insect pest management. Agricul and Human Values 11:126-39.

Hendricks LC. 1995. Almond growers reduce pesticide use in Merced county field trials. Cal Ag 49(1):5-10.

Rice RE, Jones RA. 1988. Timing postbloom sprays for peach twig borer (Lepidoptera: Gelechiidae) and San Jose scale (Homoptera: Diaspididae). J Econ Entomol 81:293-9.

Rice RE, Kirsch P. 1990. Mating disruption of oriental fruit moth in the United States. In: Ridgway RL, Silverstein RM, Inscoe MN (eds.). Behavior-Modifying Chemicals for $\mathrm{In}$ sect Management. New York: Marcel Decker. p. 193-211.

Rice RR, Zalom FG, Brunner JF. 1982. Monitoring peach twig borer development with degree-day. UC, Div Agricul Sci, Leaflet No. 21302

Shorey HH, Gaston LK, Gerber RG, et al. 1993. Disruption of foraging by Formica aerata (Hymenoptera: Formicidae) through the use of semiochemicals and related compounds. Environ Entomol 22:920-4.
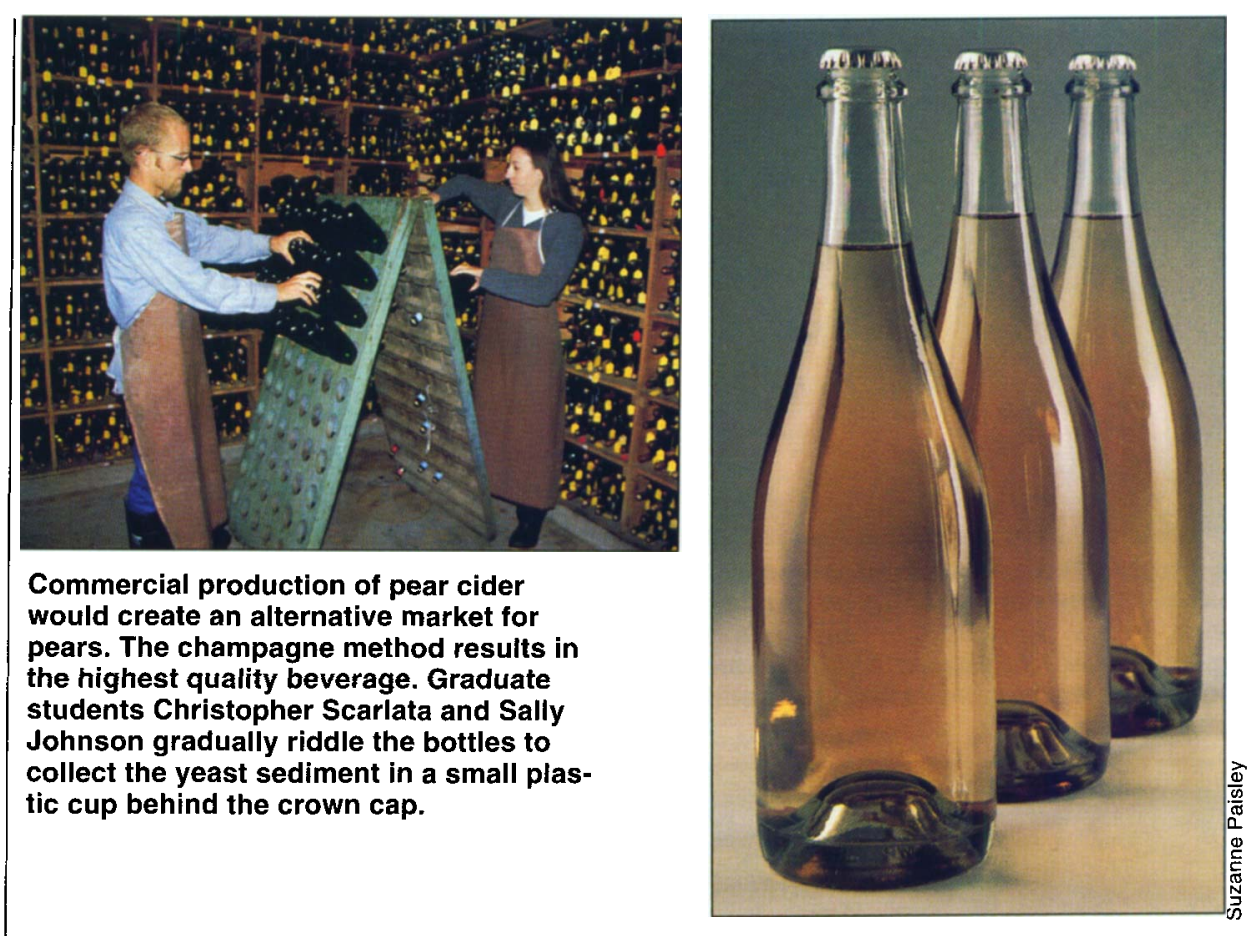

Commercial production of pear cider would create an alternative market for pears. The champagne method results in the highest quality beverage. Graduate students Christopher Scarlata and Sally Johnson gradually riddle the bottles to collect the yeast sediment in a small plastic cup behind the crown cap.

Feasibility of producing pear wine...

\title{
Pears produce premium sparkling wine
}

\author{
Glenn T. McGourty $\quad$ Christian E. Butzke
}

Pear growers and packers continue to need profitable market channels for fruit that is not packed for fresh market or canned. Off-grade fruit that is designated for the juicing market frequently gives growers and packers poor returns unless there are significant shortages of fruit juice concentrates in the marketplace.

Finding a use for these fruit in the creation of a higher priced, valueadded premium product could greatly strengthen the performance of this segment of the pear market and at the same time use the off-season production capacity of sparkling wineries. Our experiments demonstrate that an ultrapremium-quality cider can be made from juice grade Bartlett pears. Pear fruit should be ripe for optimum flavors and aromas.
In Northern Europe, a sparkling alcoholic beverage is made from both pears and apples. Cider, or cidre, by definition is fermented juice of apples or pears. These beverages are usually between $4 \%$ and $7 \%$ alcohol and generally retain some carbon dioxide, so that they have "fizz," much like beer. The British Isles and Northern France consume large amounts of both apple cider and perry (pear cider). Presently, among consumers 21 to 30 years of age in those countries (the legal drinking age is 16 in most of Europe), cider and perry are the most popular alcoholic beverages after beer. In the last 10 years, Britain has seen a steady consumption of cider, which makes up $10 \%$ of the beverages sold in pubs (Berger 1995). Today, the UK cider market exceeds 100 million gallons.

Ciders were widely enjoyed in early American society. Apple trees grew extremely well in New England, and 